\title{
Low-dose radiation-induced apoptosis in human leukemia K562 cells through mitochondrial pathways
}

\author{
YONG XIN $^{1 *}$, HAI-BIN ZHANG ${ }^{2 *}$, TIAN-YOU TANG ${ }^{1}$, GUI-HONG LIU ${ }^{1}$, \\ JIAN-SHE WANG ${ }^{1}$, GUAN JIANG ${ }^{3}$ and LONG-ZHEN ZHANG ${ }^{1}$ \\ ${ }^{1}$ Department of Radiotherapy, Affiliated Hospital of Xuzhou Medical College, Xuzhou, Jiangsu 221002; \\ ${ }^{2}$ Department of Radiotherapy, Huzhou Central Hospital, Huzhou, Zhejiang 313000; \\ ${ }^{3}$ Jiangsu Key Laboratory of Biological Cancer Therapy, Xuzhou Medical College, \\ Xuzhou, Jiangsu 221002, P.R. China
}

Received September 14, 2013; Accepted October 23, 2013

DOI: $10.3892 / \mathrm{mmr} .2014 .2381$

\begin{abstract}
High-dose total body irradiation (TBI) has an established role as preparative regimen for bone-marrow transplantation in the treatment of chronic myelogenous leukemia (CML), but this regimen still has a relatively high rate of acute and late toxicity. Low-dose radiation (LDR) induces apoptosis of tumor cells and has numerous beneficial effects on normal tissues, including radiation homeostasis and adaptive response. Based on the previous evidence, in the present study, K562 cells were exposed to LDR, high-dose radiation (HDR), and LDR in combination with HDR to investigate the possible mechanism of the apoptotic effect and hypersensitivity induced by LDR. The apoptotic rate increased in all radiation groups in a time-dependent manner. An upregulation of Bax protein expression and a downregulation of $\mathrm{Bcl}-\mathrm{xl}$ in a dose-dependent manner in human leukemia K562 cells was observed. However, the expression of $\mathrm{p} 53$ protein did not change in all of the radiation cell groups. The mitochondrial membrane potential $(\Delta \Psi \mathrm{m})$ in $\mathrm{K} 562$ cells decreased in all of the radiation cell groups in a dose-dependent manner. Furthermore, the decrease of $\Delta \Psi \mathrm{m}$ was enhanced in the LDR/HDR group compared with that in the LDR or HDR groups. The activity of caspase- 3 was enhanced in all of the radiation groups. In the LDR/HDR group, the activity of caspase-3 was higher than that in the HDR or LDR groups. The present study provided preliminary experimental evidence of LDR being beneficial in combination with TBI in the treatment of CML.
\end{abstract}

Correspondence to: Professor Long-Zhen Zhang, Department of Radiotherapy, Affiliated Hospital of Xuzhou Medical College, 99 West Huai-Hai Road, Xuzhou, Jiangsu 221006, P.R. China E-mail: deep963@163.com

*Contributed equally

Key words: low-dose radiation, apoptosis, K562, hypersensitivity, leukemia

\section{Introduction}

Radiation therapy has wide clinical utility, particularly in the treatment of solid tumors (1). The application of radiation therapy in hematological malignancies initially began in the 1920s, using the technique of low-dose total body irradiation (LDBI) for the treatment of low-grade malignant non-Hodgkin's lymphoma and chronic lymphocytic leukemia, which achieved notable efficacy (2-4).

Until the middle of the 20th century, high-dose total body irradiation (TBI) replaced LDBI in the pretreatment of bone marrow transplantation, establishing a classic conditioning regimen of TBI/CY that remains in use today. TBI has an established role as a preparative regimen for bone-marrow transplantation in the treatment of hematological malignancies. Numerous randomized trials have demonstrated that the clinical outcomes obtained from the combination of TBI and cyclophosphamide are equivalent to those based on chemotherapeutic agents, and are occasionally better than them. Despite the therapeutic progress and the improvement in the overall survival in recent years, this preparative regimen still has a relatively high rate of acute and late toxicity, including gastrointestinal toxicity, infections, hemorrhagic cystitis, hepatic veno-occlusive disease (VOD), acute graft-versus-host disease (aGVHD) and interstitial pneumonia (IP). Given the limitations of radiation therapy, novel treatment strategies that overcome acquired toxicity are urgently required.

Luckey (5) first proposed the excitatory effect produced by low-dose irradiation (LDR). The study's experimental results demonstrated that moderate LDR is not only harmless to humans, but also beneficial to life activity by promoting fertility and reproduction, increasing physical defense capability, producing self-adaptability and enhancing damage repair ability. It is, however, the apparent anti-tumor, radiation hypersensitivity and self-adaptive effects, which were generated by LDR, that raised marked concern amongst oncologists.

LDR is a type of irradiation with a radiation dose of $<20 \mathrm{c} \mathrm{Gy}$ (low LET) and $<5 \mathrm{c}$ Gy (high LET), with a dose rate that ranges between $5-10 \mathrm{c} \mathrm{Gy} / \mathrm{min}$. LDR confers significant benefits by inducing a radio-adaptive response, where pre-irradiation with 
low doses allows the body to produce an adaptive response to subsequent high-dose irradiation, thereby reducing the radiation damage effect caused by high doses radiation. Olivieri et al (6) first proposed that a low-level radiation may induce genetic self-adaptive responses in human lymphocytes, including cytogenetic, gene mutation, cell survival as well as immune adaptive responses.

The possible mechanisms responsible for the difference in the induction of radio-adaptive response by LDR between normal tissues and tumor cells have remained controversial. Hendrikse et al (7) demonstrated that p53 has an important role in determining the LDR-induced adaptive response. However, evidence exists that does not support the significance of p53 in the induction of radioresistance by LDR. Seong et al (8) demonstrated that radio adaption or radio sensitivity induced by LDR was independent of the expression of p53 in the tumor cells, which may be associated with members of the B-cell lymphoma 2 (Bcl-2) family.

In view of the biological characteristics of LDR and the limitation caused by radiation toxicity of TBI clinically, it is highly important that the adaptive response induced by the LDR may be able to alleviate the subsequent high dose of TBI treatment toxicity if combining LDR with TBI. However, whether LDR is able to induce radioadapative responses remains dependent on several factors, including cell types (9).

K562 is the human erythroleukemia cell line of CML in the blastic phase (10). Bcl-2 extra large (Bcl-xl), the inhibitory apoptosis protein of the $\mathrm{Bcl}-2$ family, has a similar function to Bcl-2 in inhibiting apoptosis of tumor cells by a variety of mechanisms, including inhibiting the decrease of the mitochondrial membrane potential $(\Delta \Psi \mathrm{m})$. Bcl-2-associated $\mathrm{X}$ (Bax), the apoptosis-promoting protein, mainly promotes the decrease of $\Delta \Psi \mathrm{m}$ through the formation of retinoid $\mathrm{X}$ receptor (RXR)-RXR, resulting in the subsequent induction apoptosis. $\mathrm{p} 53$, the apoptosis activating gene, is involved in apoptosis regulation through multiple pathways. K562 is the 135th codon insertion mutation of p53 RNA, which leads to a complete loss of function of p53. K562 has a marked resistance to chemotherapy and radiotherapy (11).

The present study aimed to detect the anti-tumor effect of LDR and LDR/HDR to K562 cells in vitro and to examine their possible mechanisms with the purpose of providing experimental evidence for the feasibility of the conditioning regimen, TBI combined with $\mathrm{LDR}$, as a pre-transplant conditioning regimen in the treatment of leukemia.

\section{Materials and methods}

Cell lines and culture conditions. The human cell line K562 was a gift from Jiangsu Institute of Hematology, Suzhou University First Hospital (Jiangsu, China). The cells were cultured in RPMI-1640 (Gibco-BRL, Carlsbad, CA, USA) supplemented with $10 \%$ heat inactivated fetal bovine serum (FBS; Gibco-BRL), 4 mM glutamine (Santa Cruz Biotechnology, Inc., Santa Cruz, CA, USA), $50 \mathrm{U} / \mathrm{ml}$ penicillin and $50 \mu \mathrm{g} / \mathrm{ml}$ streptomycin (Gibco-BRL) at $37^{\circ} \mathrm{C}$ in a humidified atmosphere with $5 \% \mathrm{CO}_{2}$. The cells were screened routinely to verify the lack of mycoplasma contamination and used in the long phase of growth.
Experimental classification. The K562 cells in the long phase of growth were divided into four groups (ten subgroups), including a blank control group (0 Gy; BC group), a low-dose radiation group (LDR group), a high-dose radiation group (6 Gy, HDR group) and a low-dose radiation combined with high-dose radiation group (LDR/HDR group). The LDR groups were re-divided into four subsets according to the irradiation dose: 0.08 Gy, 0.2 Gy, 0.5 Gy and 0.8 Gy. LDR/HDR groups were divided into four subsets: $0.08 \mathrm{~Gy} / 6 \mathrm{~Gy}, 0.2 \mathrm{~Gy} / 6 \mathrm{~Gy}$, $0.5 \mathrm{~Gy} / 6 \mathrm{~Gy}$ and $0.8 \mathrm{~Gy} / 6 \mathrm{~Gy}$. Each dosage group was assayed in triplicate.

Irradiation conditions. The K562 cells were cultivated in flasks, covered with a $1.5 \mathrm{~cm}$ lucite plate and irradiated at the different doses with $6 \mathrm{MV}$ X-rays (Clinac 23EX, Varian, Palo Alto, CA, USA) using a $20 \mathrm{~cm}$ x $20 \mathrm{~cm}$ irradiation field and $100 \mathrm{~cm}$ of source skin distance, with dose rates of $0.05 \mathrm{~Gy} / \mathrm{min}$ for LDR and $2 \mathrm{~Gy} / \mathrm{min}$ for HDR. LDR was administered $12 \mathrm{~h}$ prior to HDR. The cell cultures were maintained in cultivation and harvested at the time-points of 24, 48, 72, 96 and $120 \mathrm{~h}$ following irradiation at $37^{\circ} \mathrm{C}$ in $5 \% \mathrm{CO}_{2}$ with saturated humidity.

Measurement of apoptosis. Apoptosis was examined using a fluorescein isothiocyanate (FITC)-labeled Annexin V/propidium iodide (PI) apoptosis detection kit (BD Pharmingen, San Diego, CA, USA) according to the manufacturer's instructions. Briefly, $1 \times 10^{6} \mathrm{~K} 562$ cells were harvested and washed twice with cold phosphate-buffered saline (PBS). The cells were then resuspended in $250 \mu \mathrm{l} 1 \mathrm{x}$ binding buffer. Next, $5 \mu \mathrm{l}$ Annexin V-FITC and $5 \mu \mathrm{l}$ PI were added. Flow cytometric analysis was performed immediately following staining. The data acquisition and analysis were performed on a fluorescence-activated cell scanner (FACScan) flow cytometer (Becton Dickinson, San Jose, CA, USA). Cells in the early stages of apoptosis were Annexin V-positive and PI-negative, whereas the cells in the late stages of apoptosis were both Annexin V and PI-positive.

Western blot analysis. To determine the pre- and post radiation expression of Bcl-xl, Bax and p53 proteins, western blot analysis was performed. The cells were harvested from the plates, and aliquots of cell extracts were separated by $12 \%$ SDS-PAGE. The proteins were then transferred to a nitrocellulose membrane and incubated overnight at $4{ }^{\circ} \mathrm{C}$ with the following rabbit polyclonal antibodies: Anti-p53, anti-Bcl-xl, anti-Bax (Cell Signaling Technology, Inc., Beverly, MA, USA) and anti- $\beta$-actin antibodies (Santa Cruz Biotechnology, Inc., Santa Cruz, CA, USA), respectively. The membranes were then washed and incubated with alkaline phosphatase conjugated secondary antibodies in TBST (Tris-buffered saline with Tween-20) for $2 \mathrm{~h}$ and developed using a nitro blue tetrazolium/5-bromo-4-chloro-3-indolyl phosphate color substrate (Promega Corporation, Madison, WI, USA). The density of the protein bands on the membrane were scanned and analyzed with an image analyzer (Labworks software; UVP, Inc., Upland, CA, USA).

Assay of $\Delta \Psi m$. The $\Delta \Psi \mathrm{m}$ was determined by flow cytometry using $\mathrm{J}$-aggregate-forming lipophilic cationic probe 
A

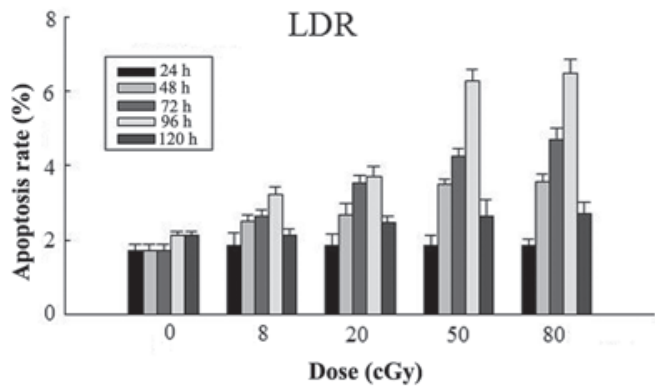

C

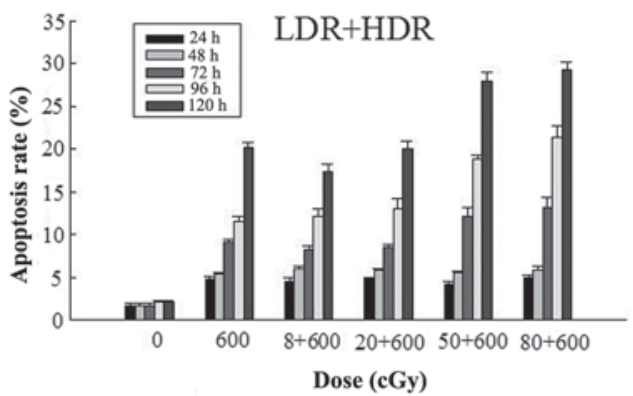

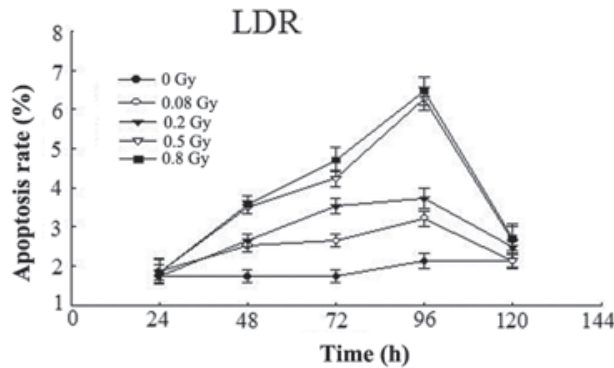

D

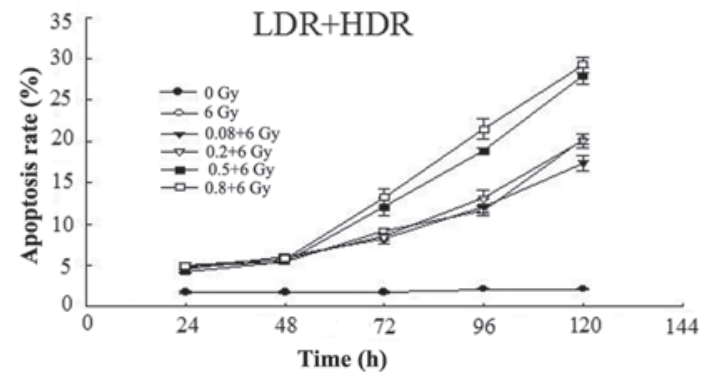

Figure 1. Apoptotic rate of K562 cells following ionizing radiation detected through annexin V-fluorescein isothiocyanate/propidium iodide staining and flow cytometric analysis. (A) Comparison of K562 apoptotic rate with various radiation doses at different time-points in LDR groups (24-120 h). (B) Apoptotic rate at different time-points with equal radiation doses in LDR group (0c Gy-80c Gy). (C) Comparison of cell apoptotic rate in LDR+HDR groups at different time-points with various dose levels. (D) Comparison of cell apoptotic rate in LDR+HDR groups with various doses at different time-points. LDR, low dose radiation; HDR, high dose radiation.

JC-1 (5,5',6,6'-tetrachloro-1,1',3,3'-tetraethylbenzimidazol carbocyanine iodide) following the manufacturer's instructions (Molecular Probes, Eugene, OR, USA). The $\Delta \Psi \mathrm{m}$ was estimated by flow cytometry following staining with JC-1 fluorescent dye. When the cell is in a normal state, $\Delta \Psi \mathrm{m}$ is high and JC-1 predominantly appears as red fluorescence. When the cell is in an apoptotic or necrotic state, the $\Delta \Psi \mathrm{m}$ is reduced and $\mathrm{JC}-1$ appears as a monomer indicated by green fluorescence. A change in fluorescence from red to green indicates a decrease in the $\Delta \Psi \mathrm{m}$. A total of $5 \times 10^{5} / \mathrm{ml} \mathrm{K562} \mathrm{cells}$ in six-well plates were treated with various concentrations of curcumin for $24 \mathrm{~h}$, then washed with PBS and incubated in the dark with JC-1 working solution for $20 \mathrm{~min}$ at $37^{\circ} \mathrm{C}$. The cells were washed with PBS and resuspended in $500 \mu \mathrm{l}$ PBS. The stained cells were analyzed by flow cytometry to determine the change in fluorescence from red to green.

Assay of caspase-3 activity. Caspase-3 activity was assessed using the caspase-3 colorimetric assay kit (Sigma-Aldrich, St. Louis, MO, USA), following the manufacturer's instructions. This assay is based on the detection of the amount of $N$-acetyl-Asp-Glu-Val-Asp- $p$-nitroanilide (Ac-DEVD- $p$-NA) substrate cleaved by cell lysates to release the colored $p$-NA molecule. In the present study, PANC-1 cells were exposed to punctata extract (100 $\mu \mathrm{g} / \mathrm{ml}$; Sigma-Aldrich) or staurosporine $(0.1 \mu \mathrm{g} / \mathrm{ml})$. Following radiation, the cells were washed in PBS and suspended in lysis buffer [50 $\mathrm{mM}$ hydroxyethyl piperazineethanesulfonic acid (HEPES) pH 7.4, $5 \mathrm{mM}$ cholamidopropyl dimethylammonio-1-propanesulfonate (CHAPS) and $5 \mathrm{mM}$ dithiothreitol (DTT)] for $15 \mathrm{~min}$ at a concentration of $10^{7}$ cells per $100 \mu \mathrm{l}$ buffer. The lysed cells were centrifuged at $16,000 \times \mathrm{g}, 4^{\circ} \mathrm{C}$ for $15 \mathrm{~min}$. The protein concentrations in lysates were determined using the Bradford assay. Equal amounts of protein $(20 \mu \mathrm{g})$ from each sample were added to wells containing the assay buffer (20 mM HEPES, pH 7.4, $0.1 \%$ CHAPS, $5 \mathrm{mM}$ DTT, $2 \mathrm{mM}$ EDTA), followed by $10 \mu \mathrm{l}$ of Ac-DEVD-p-NA (20 mM), bringing the total volume of each well to $100 \mu \mathrm{l}$. The caspase-3 activity was assessed by measuring the optical density (OD) at $405 \mathrm{~nm}$ using an enzyme mark instrument (Multiskan MK3; Thermo Labsystems, Waltham, MA, USA). All of the experiments were performed in duplicate and repeated at least three times.

Statistical analysis. Data are expressed as the mean \pm standard deviation. The significance of the differences between groups was determined using one-way analysis of variance and the Student-Newman-Keuls q-test for intergroup comparison using SPSS statistical software version 13 (SPSS, Inc., Chicago, IL, USA). $\mathrm{P}<0.05$ was considered to indicate a statistically significant difference.

\section{Results}

Effect of LDR on apoptosis in K562 cells. Compared with the control group, the number of apoptotic K562 cells in all of the LDR groups increased marginally at 24 and $120 \mathrm{~h}$ following radiation; however, the difference was not statistically significant $(\mathrm{P}>0.05)$. Notably, the apoptotic rate of K562 cells in all of the LDR groups increased markedly at 48, 72 and $96 \mathrm{~h}$, with statistically significant differences when compared with the control group. The apoptotic rate of K562 cells increased in the LDR group with statistical significance compared with the control group $(\mathrm{P}<0.01)$. In the $0.5 \mathrm{~Gy}$ group, the apoptotic rate of K562 cells increased to $4.24 \pm 0.22 \%$ at $72 \mathrm{~h}, 6.28 \pm 0.30 \%$ 
Table I. The gray scale of Bcl-xl at $24 \mathrm{~h}$ following low-dose radiation.

\begin{tabular}{lcccccccc}
\hline Dose (c Gy) & 0 & 20 & 50 & 80 & 600 & $20+600$ & $50+600$ & $80+600$ \\
\hline $\begin{array}{l}\text { The gray value } \\
\text { of Bcl-xl }\end{array}$ & $3.96 \pm 0.08$ & $3.44 \pm 0.18$ & $2.65 \pm 0.30$ & $2.07 \pm 0.31$ & $2.59 \pm 0.48$ & $2.40 \pm 0.24$ & $1.67 \pm 0.30$ & $1.19 \pm 0.08$ \\
\hline
\end{tabular}

Bcl-xl, B-cell lymphoma 2 extra large.
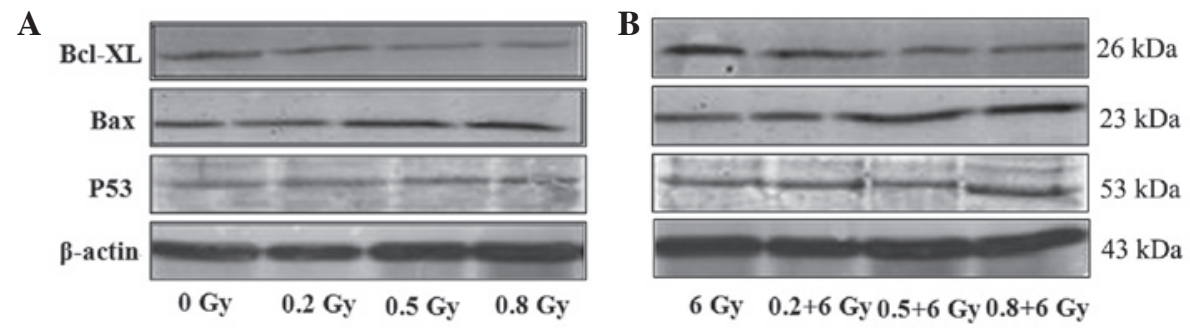

Figure 2. Expression levels of Bcl-2 family members and p53 proteins in K562 cells following LDR or LDR/HDR. (A) K562 cells were treated with diffent doses of LDR. Following treatment for $24 \mathrm{~h}$, the cell extracts were subjected to western blot analysis for assessment of apoptotic protein Bax, anti-apoptotic protein Bcl-xl and p53. (B) K562 cells were treated with LDR plus HDR. Following treatment for $24 \mathrm{~h}$, protein expression levels were detected by western blot analysis. LDR, low dose radiation; HDR, high dose radiation; Bcl-2, B-cell lymphoma 2; Bcl-xl, Bcl-2 extra large; Bax, Bcl-2-associated X.

at $96 \mathrm{~h}, 4.71 \pm 0.31 \%$ at $72 \mathrm{~h}$ and $6.47 \pm 0.37 \%$ at $96 \mathrm{~h}$ following irradiation. The 0.8 Gy group exhibited statistically significant differences at different time-points $(\mathrm{P}<0.05)$ following irradiation. The apoptotic rate of $\mathrm{K} 562$ cells increased to $2.52 \pm 0.15 \%$ at $48 \mathrm{~h}, 2.64 \pm 0.17 \%$ at $72 \mathrm{~h}, 3.21 \pm 0.20 \%$ at $96 \mathrm{~h}$ in the 0.08 Gy group, and $2.68 \pm 0.31 \%$ at $48 \mathrm{~h}, 3.52 \pm 0.20 \%$ at $72 \mathrm{~h}, 3.72 \pm 0.26 \%$ at $96 \mathrm{~h}$ in the $0.2 \mathrm{~Gy}$ group following irradiation, exhibiting no statistically significant differences at each identical time-point ( $\mathrm{P}>0.05$; Fig. 1).

Effect of LDR/HDR on apoptosis in K562 cells. The apoptotic rate of K562 cells markedly increased at $24 \mathrm{~h}$ following radiation in the HDR group, peaking at $120 \mathrm{~h}(17.38 \pm 0.92 \% \sim 29.27 \pm 0.93 \%)$, with statistically significant differences when compared with the control group $(\mathrm{P}<0.01)$. The apoptotic rate of $\mathrm{K} 562$ cells in the two LDR/HDR groups (0.08 Gy+6 Gy, 0.2 Gy+6 Gy) demonstrated no statistically significant differences when compared with the HDR group at identical time points $(\mathrm{P}>0.05)$. Notably, the apoptotic rate of the K562 cells in the LDR/HDR groups (0.5 Gy+6 Gy, 0.8 Gy+6 Gy) enhanced significantly with the dose increase of LDR in the other two LDR/HDR groups at $72 \mathrm{~h}$, peaking at $120 \mathrm{~h}(27.91 \pm 1.07 \% \sim 29.27 \pm 0.93 \%)$ following radiation in comparison with the HDR groups at the same time points $(\mathrm{P}<0.01$; Fig. 1).

Bcl-xl protein expression is downregulated by LDR alone or in combination with HDR (LDR/HDR). The expression of Bcl-xl protein in $\mathrm{K} 562$ cells changed in a dose-dependent manner at $24 \mathrm{~h}$ following radiation. Western blot analysis showed that the expression levels of Bcl-xl protein were 2.65 \pm 0.30 (0.5 Gy) and $2.07 \pm 0.31(0.8 \mathrm{~Gy})$ at $24 \mathrm{~h}$ following radiation, which were evidently lower than those in the 0.2 Gy radiation $(3.44 \pm 0.18)$ and the blank control $(3.96 \pm 0.08 ; \mathrm{P}<0.05)$ groups. The Bcl-xl protein expression was reduced even further in the combined LDR/HDR group (6 Gy) as compared with that in the LDR group in K562 cells (Fig. 2; Table I).
Bax protein expression is upregulated by $L D R$ alone or in combination with HDR. The Bax protein expression in K562 cells changed in a dose-dependent manner. Using western blot analysis, the expression of Bax in all of the LDR groups exhibited a significant difference compared with the control group (0 Gy) at $24 \mathrm{~h}$ following radiation. However, in the combined LDR/HDR group ( $6 \mathrm{~Gy}$ ), the Bax protein expression levels were notably higher in the K562 cells than those in either the LDR or HDR groups at $24 \mathrm{~h}$ following radiation ( $\mathrm{P}<0.01$; Fig. 2).

Wild-type p53 protein expression is unaltered by LDR or $L D R / H D R$ treatment. At $24 \mathrm{~h}$ following radiation, the $\mathrm{p} 53$ protein levels in K562 cells demonstrated no significant differences between either the LDR groups or the LDR/HDR group (P>0.05; Fig. 2).

Change in $\triangle \Psi m$ by $L D R$ or $L D R / H D R$. One of the early critical events in apoptosis is the loss/disruption of $\Delta \Psi \mathrm{m}$ in cells, which eventually causes the initiation and activation of apoptotic cascades. The present study examined the $\Delta \Psi \mathrm{m}$ in K562 cells by flow cytometry with JC-1 staining. Following $24 \mathrm{~h}$, the results demonstrated that treatment of K562 cells with LDR resulted in a decreasing number of green fluorescence-positive cells (indicating loss of $\Delta \Psi \mathrm{m})$ in a dose-dependent manner. The ratios of red to green fluorescence in the $0.5 \mathrm{~Gy}(5.03 \pm 0.08)$ and $0.8 \mathrm{~Gy}$ $(4.58 \pm 0.07)$ groups were significantly different compared with those in the control $(5.60 \pm 0.11),(0.08$ Gy) $5.57 \pm 0.20$ and 0.2 Gy $(5.45 \pm 0.17)$ groups $(\mathrm{P}<0.05)$. A higher proportion of green fluorescence-positive cells was detected in the LDR/HDR-treated K562 cells compared with the LDR cells $(\mathrm{P}<0.01)$. These results indicated that LDR or LDR/HDR induced a loss of $\Delta \Psi \mathrm{m}$ in $\mathrm{K} 562$ cells at $24 \mathrm{~h}$ following radiation, which was more evident in the LDR/HDR group than that in the LDR group (Fig. 3). 


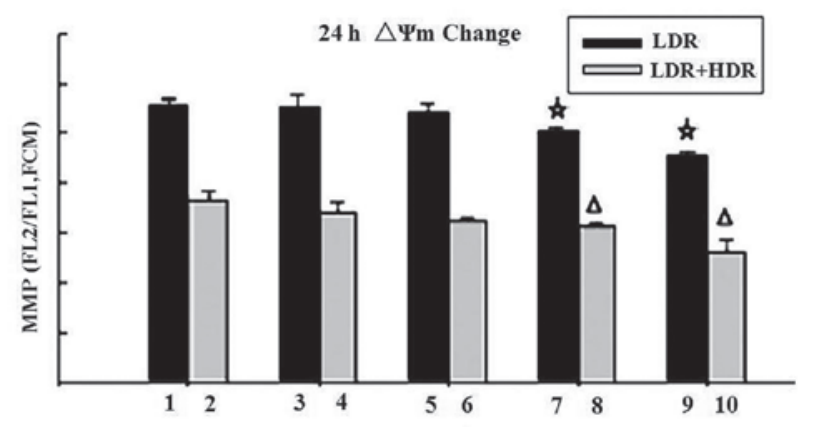

$1,0 \mathrm{~Gy} ; 2,0+6 \mathrm{~Gy} ; 3,0.08 \mathrm{~Gy} ; 4,0.08+6 \mathrm{~Gy} ; 5,0.2 \mathrm{~Gy}$; $6,0.2+6 \mathrm{~Gy} ; 7,0.5 \mathrm{~Gy} ; 8,0.5+6 \mathrm{~Gy} ; 9,0.8 \mathrm{~Gy} ; 10,0.8+6 \mathrm{~Gy}$

Figure 3. Change of $\Delta \Psi \mathrm{m}$ by LDR or LDR/HDR at $24 \mathrm{~h}$ following radiation $\left({ }^{\Delta / 2} \mathrm{P}<0.05\right.$ vs. control). $\Delta \Psi \mathrm{m}$, mitochondrial membrane potential; LDR, low dose radiation; HDR, high dose radiation.

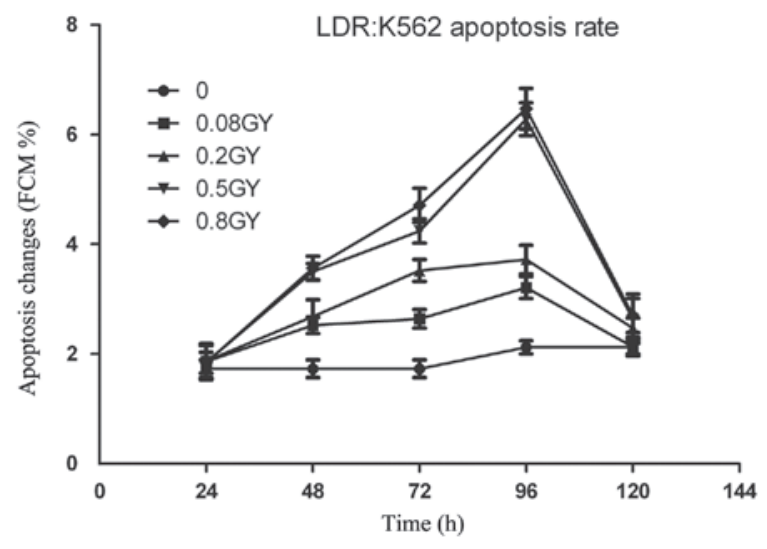

Figure 4. $\Delta \Psi \mathrm{m}$ decrease and caspase-3 activation increase at $24 \mathrm{~h}$ of LDR ( $\mathrm{P}<0.05$ vs. control or positive). $\Delta \Psi \mathrm{m}$, mitochondrial membrane potential; LDR, low dose radiation.

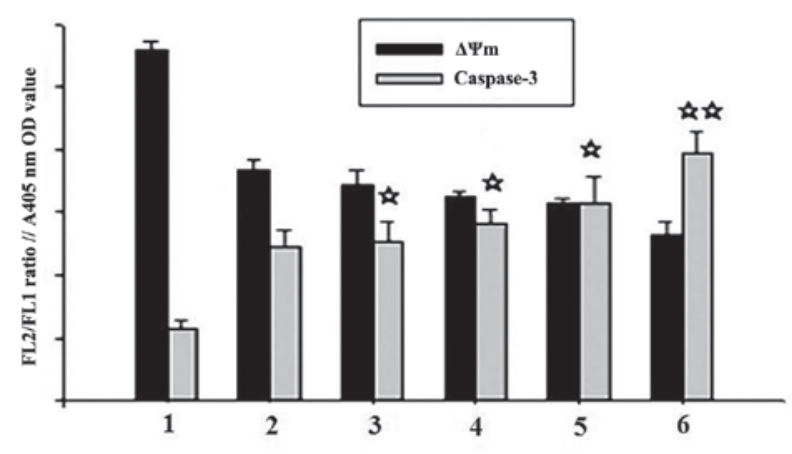

$1,0 \mathrm{~Gy} ; 2,6 \mathrm{~Gy} ; 3,0.08+6 \mathrm{~Gy} ; 4,0.2+6 \mathrm{~Gy} ; 5,0.5+6 \mathrm{~Gy} ; 6,0.8+6 \mathrm{~Gy}$

Figure 5. $\Delta \Psi \mathrm{m}$ decrease and caspase-3 activation increase at $24 \mathrm{~h}$ following LDR+HDR ( $\mathrm{P}<0.05$ vs. control or $0 \mathrm{~Gy}$; 弥 $\mathrm{P}<0.01$ vs. control or $0 \mathrm{~Gy}$ ). $\Delta \Psi \mathrm{m}$, mitochondrial membrane potential; LDR, low dose radiation; HDR, high dose radiation.

Measurement of caspase-3 activities. Caspase-3 activation is a crucial component in the apoptotic signaling cascade. To further elucidate the mechanism of cell apoptosis induced by irradiation, a caspase- 3 colorimetric assay was conducted to assess the levels of caspase-3 activation in cells at $24 \mathrm{~h}$ following LDR or LDR/HDR treatments. LDR mildly increased caspase-3 activity with a statistically significant difference among the LDR groups $(\mathrm{P}<0.05)$. Furthermore, when the K562 cell cultures were co-treated with LDR and HDR, the activity of caspase-3 was increased significantly compared with that in the cells treated with HDR alone $(\mathrm{P}<0.05$; Figs. 4 and 5).

\section{Discussion}

LDR is able to induce a number of biological effects on the tissues of the body or cell cultures, including radiation homeostasis, adaptive response, hyper-sensitivity and bystander effect (12). Experimental studies suggested that the efficacy of LDBI is mainly attributed to the mechanisms of immune enhancement (13-18), induction of apoptosis $(19,20)$, intrinsic hypersensitivity (21) and contribution of antioxidant enzymes to low-radiation doses (22). These effects are not mutually exclusive, and it is quite plausible that more than one mechanism is functional at the same time, or that they all work simultaneously.

Numerous human tumor cell lines exhibit a low-dose hyper-sensitivity to radiation, known as hyperradiosensitivity (HRS). This is most commonly manifested $<0.5$ Gy as a clear deviation from the standard linear-quadratic cell survival response extrapolated from higher doses back to $0 \mathrm{~Gy}$. It is accompanied by an increase in radioresistance between 0.5 and $1 \mathrm{~Gy}$, known as increased radioresistance. Hypersensitivity to radiation is one of the leading mechanisms involved in the induction of tumor cell apoptosis. Enns et al (23) examined the response of human A549 lung carcinoma and T98G glioma cells to $\gamma$-radiation from doses of $0-2$ Gy delivered at 0.18 and $0.22 \mathrm{~Gy} / \mathrm{min}$, and observed that there was a marked hypersensitivity at radiation doses $<0.5 \mathrm{~Gy}$. In this study it was also suggested that low-dose hypersensitivity is associated with p53-dependent apoptosis. A possible explanation is that at very low-acute doses, cells do not to upregulate radioprotective repair mechanisms to repair damage and instead, apoptosis is initiated (24). Furthermore, other evidence supported the existence of a correlation between the enhanced low-dose cell death and apoptosis. It was demonstrated that low-dose HRS is likely to be a measure of the apoptosis of radiation-damaged G2-phase-specific cells that evade early G2-phase checkpoint arrest (25). A three-component model of hypersensitivity was proposed that consisted of damage recognition, signal transduction and DNA damage repair. The foundation of the model is a rapidly occurring dose-dependent pre-mitotic cell cycle checkpoint that is specific to cells exposed to irradiation whilst in G2 phase (26). Olive and Durand (27) studied the apoptotic mechanisms of hematopoietic cell lines, finding that they generally undergo rapid apoptosis (within hours) following radiation, in contrast to cells of non-hematopoietic origin, which are more likely to be characterized by delayed apoptosis (within days). Tolerance for DNA damage appears to be reduced in cells capable of rapid apoptosis, and those hematopoietic cells are sensitized to ionizing radiation when their apoptotic response mechanisms are fully functional. This rapid apoptotic response demonstrates minor sensitivity to the cell cycle phase or radiation dose rate. 
Various therapeutic strategies have been used for the treatment of CML. These include cytotoxic agents, including hydroxyurea, interferon- $\alpha$ (IFN- $\alpha$ )-based regimens, tyrosine kinase inhibitors (TKI) and allogeneic hematopoietic stem cell transplantation (allo-HSCT). The cumulative evidence generated thus far demonstrated that CML remains a difficult malignancy to treat, with the median survival ranging between 3-4 years. Despite the introduction of targeted therapies, such as TKI drugs, the prognosis of CML has not changed to a large extent. As a result, novel effective treatments are urgently required.

Takahashi et al (28) previously found that small doses of $\mathrm{X}$-rays accelerated the process of cell death, using a dye exclusion test in MOLT-4 cells of human T-cell leukemic origin, in which radiation-induced cell death has been well characterized to proceed via apoptosis. Chen and Sakai (29) also reported that by administering 0.2 Gy of X-rays $12 \mathrm{~h}$ prior to a challenge with $5 \mathrm{~Gy}$ irradiation, the process of apoptosis in human leukemic MOLT- 4 cells was accelerated. The acceleration was associated with an increase in caspase-3 activity, a disruption of the mitochondrial transmembrane potential and an accumulation of $\mathrm{p} 53$ proteins. This finding is in contrast to the radiation-adaptive responses in which a small dose of pre-irradiation would induce certain radiation resistance and decrease the cell death following radiation with higher doses. The studies described above performed in vitro have demonstrated that LDR may induce apoptosis in leukemia cells containing the wild-type p53 gene. This radiation-induced apoptosis requires further study.

The present study demonstrated that the increase in the apoptotic rate of K562 cells following LDR exhibits a well defined dose-dependent response. The proportion apoptotic K562 cells, particularly when exposed to 0.5 or $0.8 \mathrm{~Gy}$, was higher than in the other exposure groups. This possibly results from the high expression of Bcl-xl protein in K562 cells, which, to a certain extent, contributes to radioresistance, whereas the p53 mutation in K562 cells leads to no evident retardation in the G1 phase. Apoptosis of K562 cells under LDR increased following $48 \mathrm{~h}$ and lasted until $96-120 \mathrm{~h}$ post-irradiation, characterized by delayed apoptosis and longer apoptosis duration. Furthermore, this type of apoptosis in K562 cells had no correlation with the p53 mutation status, suggesting the possible involvement of a p53-independent apoptotic pathway, which belongs to a slow-response cell population, only progressing through mitosis before apoptosis would have occurred. Waldman et al (30) reported that in the absence of p21 or p53 in certain tumor cells DNA damage caused cell cycle arrest in the G2-like stage, but cells additionally proceeded through $\mathrm{S}$ phase without undergoing mitosis. As a result, the cells acquired grossly deformed, polyploid nuclei and subsequently died through apoptosis. This apoptosis, triggered by DNA-damaging agents that are able to trigger $\mathrm{S} / \mathrm{M}$ uncoupling, is a mechanism of the non-p53-dependent-apoptotic pathway. In the present study, it was identified that HDR combined with LDR enhanced the lethal effect to K562 cells, leading to an increased apoptotic rate and extending cell apoptosis by the same apoptosis pathway as Waldman et al previously reported. The Bcl-2 gene family has a crucial regulatory role in cell apoptosis. High expression of Bcl-2 family proteins in tumor cells is an important factor in the resistance to chemoradiation and consequently, there is a high correlation with clinical prognosis in treatment. The Bcl-xl gene is also an apoptosis-inhibiting gene in the Bcl-2 gene family. Jiang et al (31) previously observed that pre-exposure to $0.075 \mathrm{~Gy}$ of X-ray prior to $4 \mathrm{~Gy}$ of X-rays induced a higher apoptotic effect and an increased expression of apoptosis-associated genes, p53 and Bax, along with a lower expression of anti-apoptosis gene Bcl-2, in tumor cells (lung carcinoma cell line NCI-H446, glioma cell line U251, erythroleukemia cell line K562 and acute promyelocytic leukemia cell line HL60) than those in the tumor cells exposed to 4 Gy of X-rays alone. In the present study, LDR significantly decreased the expression of the Bcl-xl protein and increased the expression of Bax in a dose-dependent manner, and lowering the $\mathrm{Bcl}-\mathrm{xl} / \mathrm{Bax}$ ratio promoted the apoptosis of K562 cells. When the Bcl-xl protein expression was high, the K562 cells exhibited resistance to common chemoradiation. However, when exposed to LDR, the expression of Bcl-xl protein was downregulated, resulting in DNA damage and the induction of cell apoptosis. Of note, LDR/HDR further promoted the reduction of $\mathrm{Bcl}-\mathrm{xl}$ protein and the production of Bax protein in K562 cells, leading to a higher apoptotic rate compared with HDR alone.

The activation of the mitochondria-mediated apoptotic pathway is essential for programmed cell death. Mitochondrial membrane permeability and the alteration of membrane potentials are essential aspects in the apoptotic process, resulting in release of $\mathrm{CytoC}$ and initiation of apoptosis by activating the caspase reaction cascade. Yu et al (32) also discovered that LDR exposure $(0.0075 \mathrm{~Gy})$ increased the therapeutic efficacy of cyclophosphamide (CTX) to S180 sarcoma cells. The apoptosis of tumor cells increased significantly following LDR. The cell cycle was more significantly arrested upon exposure to LDR followed by CTX as compared with that resulting from exposure to CTX chemotherapy only. This was due to LDR+CTX inducing greater cytochrome c levels and caspase-3 activity than CTX chemotherapy only in tumor cells. The present study demonstrated that LDR significantly decreased the $\Delta \Psi \mathrm{m}$ and increased caspase- 3 activity. Furthermore, in combination with HDR, the $\Delta \Psi \mathrm{m}$ in K562 cells was severely diminished and higher caspase-3 activity was present, indicating that LDR was able to enhance the radiation efficacy of HDR. Notably, no evident change in the level of p53 protein expression occurred following combined LDR/HDR. It was therefore assumed that this result was likely owing to a mutation of p53 in K562 cells.

In conclusion, LDR was able to induce apoptosis of K562 cells and enhanced the lethal effect of HDR on K562 cells combined with HDR. It provided evidence for the feasibility of the conditioning regimen of TBI combined with LDR, as a pre-transplant conditioning regimen in the treatment of leukemia. However, to achieve this synergistic effect, a dosage of LDR between $0.5 \mathrm{~Gy}$ and $0.8 \mathrm{~Gy}$ is required. The possible mechanism of action is through the p53-independent apoptosis pathway. K562 cells would undergo DNA damage with LDR, which initiates the mitochondria-mediated apoptotic pathway, including upregulation of Bax protein expression and downregulation of $\mathrm{Bcl}-\mathrm{xl}$ protein expression, resulting in the breakdown of $\Delta \Psi \mathrm{m}$. The outer membrane of mitochondria becomes permeable to cytochrome c, and when cytochrome c is released to the cytosol, it triggers caspase cascade reactions. It is suggested that LDR in combination with HDR, when 
administered at the appropriate dosage, is able to increase the apoptotic index of HDR by accelerating apoptosis as well as increasing apoptosis duration and incidence.

\section{Acknowledgements}

This study was supported by grants from the National Natural Science Foundation of China (nos. 30770916, 81071831, 81372424 and 81372916); the Department of Science and Technology of Jiangsu Province (no. BK20131131); and the Deapartment of Science and Technology of Xuzhou (no. XM12B029).

\section{References}

1. Li J, Chen F, Cona MM, et al: A review on various targeted anticancer therapies. Target Oncol 7: 69-85, 2012.

2. Nwokocha CR, Nwokocha M, Mounmbegna P, et al: Proteins and liver function changes in rats following cumulative total body irradiations. West Indian Med J 61: 773-777, 2012.

3. WalchJ,Tettenborn B,WeberJand HundsbergerT:Radiation-induced cavernoma after total body irradiation and haematopoietic stem cell transplantation in an adult patient suffering from acute myeloid leukaemia. Case Rep Neurol 5: 91-97, 2013.

4. Nomura T, Sakai K, Ogata H and Magae J: Prolongation of life span in the accelerated aging klotho mouse model, by low-dose-rate continuous $\gamma$ irradiation. Radiat Res 179: 717-724, 2013.

5. Luckey TD: Atomic bomb health benefits. Dose Response 6: 369-382, 2008.

6. Olivieri G, Bodycote J and Wolff S: Adaptive response of human lymphocytes to low concentrations of radioactive thymidine. Science 223: 594-597, 1984.

7. Hendrikse AS, Hunter AJ, Keraan M and Blekkenhorst GH: Effects of low dose irradiation on TK6 and U937 cells: induction of 553 and its role in cell-cycle delay and the adaptive response. Int J Radiat Biol 76: 11-21, 2000.

8. Seong J, Kim SH, Pyo HR, Chung EJ and Suh CO: Effect of low-dose irradiation on induction of an apoptotic adaptive response in the murine system. Radiat Environ Biophys 40: 335-339, 2001.

9. Joksic G and Petrović S: Lack of adaptive response of human lymphocytes exposed in vivo to low doses of ionizing radiation. J Environ Pathol Toxicol Oncol 23: 195-206, 2004.

10. Czyz M and Szuławska A: Induced differentiation of the K562 leukemic cell line. Postepy Hig Med Dosw (Online) 59: 82-97, 2005 (In Polish)

11. Damiano JS, Hazlehurst LA and Dalton WS: Cell adhesion-mediated drug resistance (CAM-DR) protects the K562 chronic myelogenous leukemia cell line from apoptosis induced by BCR/ABL inhibition, cytotoxic drugs, and gamma-irradiation. Leukemia 15: 1232-1239, 2001.

12. Ito M, Shibamoto Y, Ayakawa S, Tomita N, Sugie C and Ogino H: Low-dose whole-body irradiation induced radioadaptive response in C57BL/6 mice. J Radiat Res 48: 455-460, 2007.

13. Hosoi Y: Antitumor effects by low dose total body irradiation. Yakugaku Zasshi 126: 841-848, 2006 (In Japanese).
14. Safwat A: The role of low-dose total body irradiation in treatment of non-Hodgkin's lymphoma: a new look at an old method. Radiother Oncol 56: 1-8, 2000.

15. Hashimoto S, Shirato H, Hosokawa M, et al: The suppression of metastases and the change in host immune response after low-dose total-body irradiation in tumor-bearing rats. Radiat Res 151: 717-724, 1999.

16. Liu SZ, Han ZB and Liu WH: Changes in lymphocyte reactivity to modulatory factors following low dose ionizing radiation. Biomed Environ Sci 7: 130-135, 1994.

17. Nogami M, Huang JT, James SJ, Lubinski JM, Nakamura LT and Makinodan T: Mice chronically exposed to low dose ionizing radiation possess splenocytes with elevated levels of HSP70 mRNA, HSC70 and HSP72 and with an increased capacity to proliferate. Int J Radiat Biol 63: 775-783, 1993.

18. Safwat A: The immunobiology of low-dose total-body irradiation: more questions than answers. Radiat Res 153: 599-604, 2000.

19. Knoops L, Haas R, de Kemp S, et al: In vivo p53 response and immune reaction underlie highly effective low-dose radiotherapy in follicular lymphoma. Blood 110: 1116-1122, 2007.

20. Sgouros G, Knox SJ, Joiner MC, Morgan WF and Kassis AI: MIRD continuing education: Bystander and low dose-rate effects: are these relevant to radionuclide therapy? J Nucl Med 48: 1683-1691, 2007.

21. Heyer BS, MacAuley A, Behrendtsen O and Werb Z: Hypersensitivity to DNA damage leads to increased apoptosis during early mouse development. Genes Dev 14: 2072-2084, 2000.

22. Bravard A, Luccioni C, Moustacchi E and Rigaud O: Contribution of antioxidant enzymes to the adaptive response to ionizing radiation of human lymphoblasts. Int J Radiat Biol 75: 639-645, 1999.

23. Enns L, Bogen KT, Wizniak J, Murtha AD and Weinfeld M: Low-dose radiation hypersensitivity is associated with p53-dependent apoptosis. Mol Cancer Res 2: 557-566, 2004.

24. Mitchell CR and Joiner MC: Effect of subsequent acute-dose irradiation on cell survival in vitro following low dose-rate exposures. Int J Radiat Biol 78: 981-990, 2002.

25. Krueger SA, Joiner MC, Weinfeld M, Piasentin E and Marples B: Role of apoptosis in low-dose hyper-radiosensitivity. Radiat Res 167: 260-267, 2007.

26. Marples B, Wouters BG, Collis SJ, Chalmers AJ and Joiner MC: Low-dose hyper-radiosensitivity: a consequence of ineffective cell cycle arrest of radiation-damaged G2-phase cells. Radiat Res 161: 247-255, 2004.

27. Olive PL and Durand RE: Apoptosis: an indicator of radiosensitivity in vitro? Int J Radiat Biol 71: 695-707, 1997.

28. Takahashi K, Inanami O, Hayashi M and Kuwabara M: Protein synthesis-dependent apoptotic signalling pathway in X-irradiated MOLT-4 human leukaemia cell line. Int J Radiat Biol 78: 115-124, 2002.

29. Chen Z and Sakai K: Enhancement of radiation-induced apoptosis by preirradiation with low-dose X-rays in human leukemia MOLT-4 cells. J Radiat Res 45: 239-243, 2004.

30. Waldman T, Lengauer C, Kinzler KW and Vogelstein B: Uncoupling of $\mathrm{S}$ phase and mitosis induced by anticancer agents in cells lacking p21. Nature 381: 713-716, 1996.

31. Jiang H, Li W, Li X, Cai L and Wang G: Low-dose radiation induces adaptive response in normal cells, but not in tumor cells: in vitro and in vivo studies. J Radiat Res 49: 219-230, 2008.

32. Yu HS, Xue HW, Guo CB, et al: Low dose radiation increased the therapeutic efficacy of cyclophosphamide on S(180) sarcoma bearing mice. J Radiat Res 48: 281-288, 2007. 